\title{
Florid psychopathology in patients receiving shocks from implanted cardioverter-defibrillators
}

John P Bourke, Douglas Turkington, Gareth Thomas, Janet M McComb, Margaret Tynan

\begin{abstract}
Objectives-To increase awareness of the potential for disabling anxiety and depression in patients receiving shocks from implanted cardioverter-defibrillators (ICDs).

Patients and methods-ICDs are implanted in patients at this hospital for control of serious ventricular tachyarrhythmias inadequately controlled by drug treatment, who are unsuitable for map guided antiarrhythmic surgery. All are reviewed regularly at a dedicated ICD clinic and are advised to make contact between visits if they experience shocks. Symptoms of anxiety or depression were not actively sought, nor was a patient support group operating at the time of this data collection. When overt psychopathology was identified, patients were referred to a designated psychiatrist for management.
\end{abstract}

Results-Over a six year period, six (17\%) of 35 patients with ICDs developed florid psychiatric problems after experiencing shocks. None had premorbid psychiatric predisposition. Of the six patients suffering severe psychiatric problems, four were men, their age range was 30-63 years, and left ventricular ejection fraction was 18$40 \%$. All shocks were appropriate for clinical arrhythmias and ranged in frequency from two in six months to 111 in 24 hours. All six patients manifested severe anxiety, focused on fear of future shocks. Depression was also evident in three patients and two had become housebound. All responded within weeks to anxiolytic or antidepressant drugs, combined with relaxation and cognitive therapies. Ongoing psychiatric therapy was refused by one patient, and was required for between three and 18 months in the remainder. One patient died and one received a cardiac transplant during the follow up period (median 27.5 months, range 8-43). Conclusions-Because ICD implantation occurs against a complex medical background with inevitable psychological stress, all such patients should be considered at high risk for developing psychopathology.

(Heart 1997;78:581-583)

Keywords: implantable cardioverter-defibrillators; psychopathology; complications
Implantable cardioverter-defibrillators (ICDs) are established therapy for patients with recurring, life threatening ventricular tachyarrhythmias. ${ }^{1-3}$ They do not prevent arrhythmic episodes but terminate them by automatically delivering either antitachycardia pacing or direct current shocks. ${ }^{4}$ Their antiarrhythmic efficacy is not in doubt. The nature of the therapy delivered is determined by the device capability and the way it has been programmed.

By comparison with implant rates in other countries, such as the USA and Germany, ICDs have not been widely used in the UK National Health Service to date; however, implant rates are rising sharply. ${ }^{5}$ With the advent of transvenous, rather than epicardial, lead systems and with the progressive reductions in device size, implantation no longer requires a thoracotomy and devices can be implanted prepectoral, as opposed to abdominally. ${ }^{6}$ Furthermore, with increased generator life span, incorporating antitachycardia pacing options, and high quality stored electrogram recordings, ICDs have become ever more attractive to physicians as ICD efficacy does not depend on the cause of the patients' arrhythmia or even its precise type.

All patients who receive ICDs have experienced a complex and life threatening illness with inevitable psychological effects. Most patients have ischaemic heart disease or cardiomyopathy, ${ }^{78}$ have survived life threatening episodes of arrhythmia, and realise that they are at risk of future episodes. ${ }^{10}$ Their investigations, failed drug trials, and need for device therapy may contribute to their psychological vulnerability. ${ }^{11}$ However, the independent psychological effect of ICD implantation, and shock therapy in particular, on patients in this country has not been studied. Psychopathology may easily be overlooked in defibrillator review clinics, where anxiety or depression may be deemed "appropriate" to the patient's experiences and not therefore in need of specific management. ${ }^{12} 13$

This report aims to highlight the adverse psychological sequelae observed in six patients after receiving shock therapy from their ICDs, and to report their management and outcome.

\section{Materials and methods}

At the Freeman Hospital, Newcastle upon Tyne, ICD treatment is only recommended to patients with ventricular arrhythmias after comprehensive assessment and detailed discussion of their risk of recurrent episodes, the range of alternative therapies available, and the 
Table 1 Patient profiles

\begin{tabular}{llllllll}
\hline No & Age/sex & VTA aetiology & Clinical VTA & EPS result & LVEF & Shock frequency & Status (months'follow up) \\
\hline 1 & $54 \mathrm{~F}$ & Rheumatic MVR & VF & NAD & $30 \%$ & $>100$ in 24 hours & A + W (43) \\
2 & $54 \mathrm{M}$ & IDC/alcohol & SMMVT & SMMVT & $23 \%$ & 12 in 1 hour & Died LVF + VF (8) \\
3 & $63 \mathrm{M}$ & Post-MI $\times 2$ & SMMVT & SMMVT & $18 \%$ & 4 in 24 hours & A + W (43) \\
4 & $44 \mathrm{~F}$ & Post-MI/CABG & SMMVT & SMMVT & $40 \%$ & 5 in 48 hours & A + W (36) \\
5 & $43 \mathrm{M}$ & Idiopathic & VF & VF only & $61 \%$ & 7 in 2 hours & A + W (24) \\
6 & $30 \mathrm{M}$ & Post-MI & SMMVT & SMMVT & $18 \%$ & 2 in 6 months & Heart transplant (40)
\end{tabular}

*Number of shocks from the ICD in specified time leading to the psychopathology.

A + W, alive and well; CABG, coronary artery bypass graft; EPS, electrophysiology result; IDC, idiopathic dilated cardiomyopathy; LVEF, left ventricular ejection fraction; LVF, left ventricular failure; MI, myocardial infarction; MVR, mitral valve replacement; VF, ventricular fibrillation; VTA, ventricular tachyarrhythmia; SMMVT, sustained monomorphic ventricular tachycardia.

nature of device therapy. Patients receiving ICDs are those with either very poor left ventricular function or major non-cardiac co-morbidity making surgery inappropriate, or those with idiopathic ventricular fibrillation. Based in these criteria, ICDs have been implanted in 35 patients from 1989-95. All patients are followed up at regular intervals at a dedicated defibrillator clinic staffed by an electrophysiologist and a cardiology technician. Psychological status was not systematically assessed at these review appointments. Patients are also encouraged to make contact with the hospital between scheduled visits if they experience shocks. They are reviewed routinely within 24 hours of shock therapy for reassurance and device interrogation.

\section{Results}

Of the 35 patients who received ICD therapy at this hospital in the period studied, six (17\%) developed psychological problems that were sufficiently florid to prompt urgent referral for formal psychiatric evaluation. The cardiology background of each of the patients and the events precipitating the subsequent psychopathology are summarised in table 1 . The most frequent manifestations of psychopathology were profound anxiety and panic reactions centred on fear of future shock therapy. Two patients also showed depressive reactions. Table 2 summarises the nature and severity of the psychopathology identified and the management and outcome in each patient.

\section{Discussion}

The typical symptoms reported by this patient group were of generalised anxiety, manifest as palpitations, sweating, tremor, abdominal churning, and restlessness. There were also phobic anxiety symptoms, including complete agoraphobia in two. This was a panic reaction to leaving the safety of home; however, the agoraphobia was unusual in that it was linked entirely to thoughts about further shocks from the implanted defibrillator and imminent death, and not to fears of being unable to escape from crowds or crowded places. Panic symptoms with hyperventilation, paraesthesia, palpitation, difficulty in breathing, and chest pain were often present when these thought sequences occurred.

Two patients were also depressed after experiencing multiple shocks from their ICD and their symptoms included sadness, insomnia, loss of energy, loss of interest, poor appetite, and suicidal thoughts. There were prominent thoughts of hopelessness about the future. The two patients with depression also suffered from prominent anxiety symptoms.

Multiple shocks were a clear precipitant for the psychiatric disorders. The thought processes resulting from this particular event were central to the subsequent psychopathology as described in table 2 according to the International Classification of Mental and Behaviourial disorders. ${ }^{14}$ Indeed, all six patients reported profoundly anxiety provoking thoughts in relation to the defibrillator, often linked to withdrawal from social interaction.

One dominant thought pattern was identified in all six patients in this group: "If the device fires I'm going to die". This catastrophic thought about the purpose of the device fed straight into the panic cycle. ${ }^{15}$ In the panic cycle, normal stressful reactions leading to palpitation and tension headache are misinterpreted as being about to lead to catastrophic events, such as sudden death from myocardial infarction or stroke. The cycle escalates because of these thought sequences, leading to more anxiety, which in turn generates more

Table 2 Psychopathology following ICD shocks: nature, management, and outcome

\begin{tabular}{|c|c|c|c|c|}
\hline No & Diagnosis & Main symptoms & Treatment & Outcome \\
\hline 1 & $\begin{array}{l}\text { Agoraphobia with panic } \\
\text { disorder }\left(\mathrm{F} 40.1^{\star}\right)\end{array}$ & $\begin{array}{l}\text { Agitation/hyperventilation/palpitations/fear } \\
\text { of the device firing }\end{array}$ & $\begin{array}{l}\mathrm{CBT} / \text { benzodiazepines/trelaxation } \\
\text { training/psychoeducation }\end{array}$ & $\begin{array}{l}\text { Intensive treatment led to full } \\
\text { recovery after } 1 \text { year }\end{array}$ \\
\hline 2 & $\begin{array}{l}\text { Moderate depressive episode } \\
\text { (F32.1) }\end{array}$ & $\begin{array}{l}\text { Insomnia/sadness/anergia/fear of future } \\
\text { shocks }\end{array}$ & $\begin{array}{l}\text { Parozetine/benzodiazepines/ } \\
\text { relaxation training }\end{array}$ & $\begin{array}{l}\text { Recovered after one month, but died } \\
\text { after } 5 \text { months }\end{array}$ \\
\hline 3 & $\begin{array}{l}\text { Generalised anxiety disorder } \\
(\mathrm{F} 41.1)\end{array}$ & $\begin{array}{l}\text { Sweating/giddiness/thoughts of the device } \\
\text { being about to fire }\end{array}$ & $\begin{array}{l}\mathrm{CBT} / \text { relaxation training/ } \\
\text { benzodiazepines/psychoeducation }\end{array}$ & $\begin{array}{l}\text { Recovered after } 3 \text { months but very } \\
\text { reluctant to stop diazepam }\end{array}$ \\
\hline 4 & $\begin{array}{l}\text { Generalised anxiety disorder } \\
(\mathrm{F} 41.1)\end{array}$ & Anxiety/agitation/anger against the device & CBT/psychoeducation & Recovered after 3 months \\
\hline 5 & $\begin{array}{l}\text { Agoraphobia with panic } \\
\text { disorder (F40.1) }\end{array}$ & $\begin{array}{l}\text { Fear of device firing/tension/fear of leaving } \\
\text { home/panic attacks }\end{array}$ & $\begin{array}{l}\mathrm{CBT} / \text { psychoeducation/ } \\
\text { benzodiazepines }\end{array}$ & Recovered after 2 months \\
\hline 6 & $\begin{array}{l}\text { Moderate depressive episode } \\
\text { (F32.1), agoraphobia (F40.1) }\end{array}$ & $\begin{array}{l}\text { Fear of further ICD discharge/ } \\
\text { housebound/sadness }\end{array}$ & $\begin{array}{l}\text { Fluoxetine/benzodiazepines/CBT/ } \\
\text { psychoeducation }\end{array}$ & $\begin{array}{l}\text { Improved after } 3 \text { months recovered } \\
\text { after cardiac transplantation }\end{array}$ \\
\hline
\end{tabular}

* psychopathology code from international classification of mental and behavioural disorders: classification of disease; tprogressive muscular relaxation therapy with the aid of an audio tape.

CBT, cognitive therapy. 
symptoms, such as hyperventilation and paraesthesia, leading to difficulty in breathing and chest pain. In the face of this spiralling anxiety, many patients reach extremely severe levels of anxiety, which may actually precipitate tachyarrhythmias. In the face of such anxiety, two patients withdrew from social interaction altogether.

There are a number of methods of helping patients interrupt this anxiety cycle. Appropriate interventions should begin with education as to the nature and purpose of the defibrillator. The typical spectrum of anxiety and depressive symptoms needs to be explained and put into proper perspective. Appropriate patient orientated information literature is already available to give to patients suffering from anxiety disorders ${ }^{16}$ and depression ${ }^{17}$ to explain their symptoms and suggest ways of containing them. This helps the patient to realise that palpitations are not necessarily cardiac in origin, but relate to the generalised stress being suffered at the time. In conjunction with this, muscular relaxation and breathing exercises, delivered on a relaxation tape, help patients to work at reducing their general anxiety response and so control hyperventilation. A number of rational responses have been found to be helpful in the management of these patients, but they need to work hard to learn them and to appreciate their use in controlling their catastrophic thinking - for example, "A palpitation is often only anxiety, it doesn't always mean the machine is about to fire"; "The device is a tried and trusted treatment. It effectively stops the arrhythmia"; "The device is an ally not an enemy"; "Life would be very unpredictable without the implanted defibrillator"; "My best chance here is to be kind to the heart and remain calm". With practice, such self statements or rational responses have proven useful in panic related to other precipitants ${ }^{18}$ and in other situations such as depression. ${ }^{19}$

Now that the adverse ways in which some patients may react to their implanted defibrillator are understood, psychopathology may be reduced or prevented completely by training patients to develop rational responses in anticipation of shock therapy. Using patient and other support groups, the process of developing these rational responses could begin before ICD implantation. When severe psychopathology presents acutely, treatment with $\beta$ adrenergic blockade, benzodiazepines, and antidepressants may all be indicated. Benzodiazepines and low dose diazepam in particular should only be used for four to six weeks at most to avoid drug dependence and the development of tolerance and symptoms of breakthrough withdrawal. Antidepressants may be indicated in patients with depressive symptoms. As paroxetine has been licensed both for the treatment of panic disorders and depression and has less arrhythmogenic potential than some alternative antidepressant drugs, ${ }^{20}$ it may be particularly useful in this population.

Lesser degrees of psychopathology can be easily missed in cardiology clinics. Patients should therefore be questioned routinely regarding anxiety or depressive symptoms and their level of social functioning. The selfadministered Hospital Anxiety and Depression rating (HAD) questionnaire, which can be completed in two to three minutes and does not rely on somatic symptoms of anxiety, could be a useful additional screening tool in this setting. ${ }^{21}$

The university department of cardiology, Freeman Hospital is generously supported by the British Heart Foundation.

1 Fisher JD, Kim SG, Mercando AD. Electrical devices for treatment of arrhythmias. Am f Cardiol 1988;61:45A-57A Kelly PA, Cannom DS, Garan J, Mirabal GS, Harthorne JW, Hurvitz RJ, et al. The automatic implantabledefibrillator: efficacy, complications and survival in patients with malignant ventricular arrhythmias. $\mathcal{F} \mathrm{Am}$ Coll Cardiol 1988;11:1278-86.

3 Kupperman M, Luce BR, McGovern B, Podrid PJ, Bigger JT, Ruskin JN. Analysis of the cost effectiveness of the implantable defibrillator. Circulation 1990;81:91-100.

4 Bourke JP. Implantable cardioverter defibrillators. British fournal of Intensive Care 1994;4(supp1):49-54.

5 Campbell RWF. Life at a price-the implantable defibrillator. Br Heart F 1990;64:171-3.

6 Fazio GP, Veltri EP. Implantable cardioverter defibrillators: the second decade. Curr Opin Cardiol 1991;6:72-7.

7 Lloyd GG, Cawley RH. Depression or illness? A study of Lloyd GG, Cawley RH. Depression or illness? A study of
psychological symptoms after myocardial infarction. $B r f$ psychological symptoms after
Psychiatry 1983;142:120-5

8 Hackett TP, Cassem NH, Wishnie HA. The coronary care unit: an appraisal of its psychological hazards. $N$ Engl f Med 1982;279:1365-70.

9 Baker B, Kazarian SS, Dorian P, Lanphier C. Psychiatric assessment of patients with life-threatening cardiac arrhythmias. Int F Psychiatry Med 1993;23:43-53.

10 Roberts G, Owen J. The near death experience. $\mathrm{Br} F$ Psychiatry 1988;153:607-17.

11 Knowey PR. The calamity of cardioversion of conscious patients. Am f Cardiol 1988;61:1106-7.

12 Keren R, Aarons D, Veltri EP. Anxiety and depression in patients with life-threatening ventricular arrhythmias: 1991;14:181-7.

13 Fricchione GL, Olson LC, Vlay SC. Psychiatric syndromes in patients with the automatic implantable cardioverter in patients with the automatic implantable cardioverter defibrillator: anxiety, psychological depende.

14 World Health Organization. Mental disorders: glossary and guide to their classification in accordance with the ninth revision of the international classification of diseases. The ICD10 classification of mental and behaviourial disorders, Geneva: World Health Organization, 1992

15 Clark DM. A cognitive approach to panic. Behav Res Ther 1986;24:461-70.

6 Beck AT, Emery G, eds. Coping with anxiety, Appendix 1. Anxiety disorders and phobias. New York: Basic Books, 1985: $315-22$.

17 Beck AT, Greenburg R. Coping with depression. New York: Institute of Rational Living, 1973.

18 Sokal-Kessler I, Beck AT. Cognitive treatment of panic disorder [abstract]. 140th annual meeting of the American Psychiatric Association, Chicago, 14 May, 1987.

19 Murphy GE, Simmons AD, Wetzel RD, Lustman PJ. Cognitive therapy and pharmacotherapy, singly and Cognitive therapy and pharmacotherapy, singly and
together in the treatment of depression. Arch Gen Psychiatry $1984 ; 41: 33-41$.

20 Oehrberg S, Christiansen PE, Behnke K, Borup AL, Severin $\mathrm{B}$, Soegaard J, et al. Paroxetine in the treatment of panic disorder. A randomised, double blind, placebo controlled study. Br F Psychiatry 1995;167:374-9.

21 Zigmund AS, Snaith RP. Hospital anxiety depression scale. Acta Psychiatr Scand 1983;67:361-70. 